\title{
Assessment of Microneedling Devices as Transepidermal Drug Delivering System for Corticosteroid in Treatment of Hypertrophic Scars
}

\author{
AHMED A. ZIDAN, M.D.; EHAB Z. AZZAM, M.D. and HELMY EL-WAKEEL, M.D. \\ The Department of General Surgery, Plastic Surgery Unit, Faculty of Medicine, Alexandria University, Egypt
}

\begin{abstract}
Background: Hypertrophic scars are one of dermal fibroproliferative disorders which can lead to pruritus, disfigurement and pain. The use of microneedling to introduce topical agents or drugs into the dermis is a rapidly growing and popular skin/scar treatment.

Patients and Methods: This is a prospective randomized study that included 30 patients suffering from Hypertrophic scars and they are candidate for the proposed technique. Microneedling by Dermapen device with application of topical triamcinolone acetonide solution on scar tissue for three sessions with 3 weeks interval in between.

Results: During one year, 30 patients were recruited in our study, the mean age of the patients was $28.16 \pm 11.24$ (range 21-58 year) and $52 \%$ of patients were female. Lesions location were anterior chest (8), extremities (18) and back (4). Mean zero VSS scores were achieved with triamcinolone transepidermal injection in respect of scar height (week $15^{\text {th }}$ ) and pliability (week $15^{\text {th }}$ ).

Conclusion: Our results did support the capability of triamcinolone transepidermal injection using Dermapen in treatment of hypertrophic scars, with an efficient, less painful and cost-effective procedure.
\end{abstract}

Key Words: Microneedling devices - Transepidermal - Corticosteroids - Hypertrophic scars.

\section{INTRODUCTION}

Hypertrophic scars are one of dermal fibroproliferative disorders which can lead to pruritus, disfigurement and pain. Hypertrophic scars are self-limited growths that enlarge within the boundaries of a wound and then often regress over time. Many hypertrophic scars spontaneously involute within 2 years [1-3].

The appearance of an unpleasant scar, even if not erased, it can definitely be improved. The procedures for scar management can be divided into two categories; "Noninvasive techniques" and "Invasive techniques." The Noninvasive techniques include pressure/compression therapy, silicone gel, topical steroids, and chemical peels. The invasive techniques include surgical scar revision, intralesional corticosteroid injection, intralesional fluorouracil, radiotherapy, laser therapy, cryotherapy, dermabrasion [4-9].

Microneedling therapy is minimally invasive non-surgical and non-ablative procedure that involves the use of a microneedling device to create controlled skin injury. There are various skin needling devices including Dermaroller, DermapenTM and DermaStamps ${ }^{\mathrm{TM}}$. As each fine needle punctures the skin, it creates a channel or micro-wound that can be used as drug delivery channels. The use of microneedling to introduce topical agents or drugs into the dermis is a rapidly growing and popular skin/scar treatment [10-16].

In this study we evaluate the therapeutic efficacy and complications of Dermapen device, as a drug delivery system for corticosteroid into hypertrophic scars.

\section{Aim of work:}

To evaluate the therapeutic efficacy and complications of microneedling (Dermapen) device for injecting corticosteroids into hypertrophic scars resulting from burns, trauma and surgery.

\section{MATERIAL AND METHODS}

It is a prospective randomized study consisting 30 patients with hypertrophic scars.

\section{Inclusion criteria:}

Patients with hypertrophic scars resulting from burns, trauma and surgery.

\section{Exclusion criteria:}

- Patients on iso-tretinoin, corticosteroid or aspirin therapy for past 1 year. 
- Patients with keloids, family history of keloids.

- Patients with bleeding disorder.

- Patients with active viral or bacterial infection or active inflammatory lesions.

- Patients with malignant tumors.

\section{Pre-operative preparation:}

Participants were counseled, informed and explained about the procedure, its complications and about the local anesthesia. Informed written consent was taken.

\section{Procedure:}

The procedure was performed under aseptic conditions and precautions using Eutectic Mixture of Local Anesthetic (EMLA) as topical anesthetic for $60-90 \mathrm{~min}$.

The skin needling procedure was performed by passing Dermapen device Fig. (1) on the skin areas affected by hypertrophic scars. To treat scars, the device used was equipped with sterile, individuallysealed, disposable needle cartridges outfitted with 12 needles Fig. (2). The needles length was adjusted at 1.5 to $2 \mathrm{~mm}$ according to the thickness of the scar.

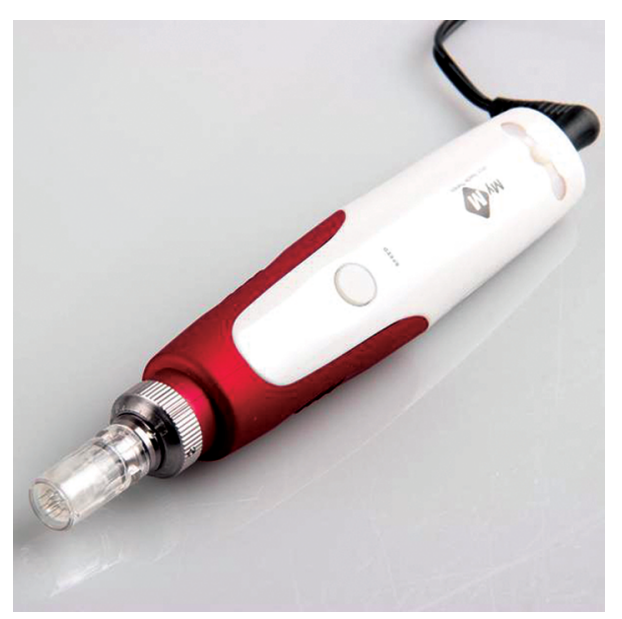

Fig. (1): Dermapen device.

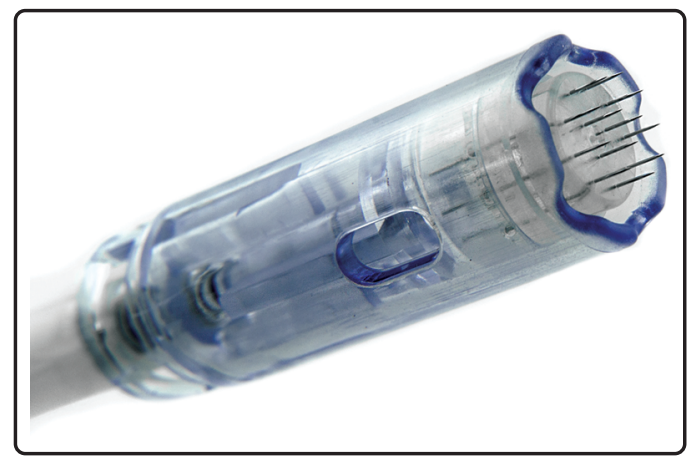

Fig. (2): Dermapen microneedles cartilage.
The procedure consisted of moving Dermapen with same pressure, 2 passes in 4 directions: Horizontally, vertically and diagonally to the right and left. This ensured an even pricking pattern resulting in about 700-750 pricks per square centimeter. After that triamcinolone acetonide $40 \mathrm{mg} / \mathrm{mL}$ solution was applied to the treated area and another 2 passes in the same directions was done. This is the last step with the aim to push the drug into the dermis through the channels performed by microneedling device. The treatment time ranged from 10 to $60 \mathrm{~min}$, depending on the size of the area being treated. The skin bleeding was observed for a short time, but that soon stopped. This procedure was repeated for 3 times with an interval 3 weeks in between (Fig. 3).

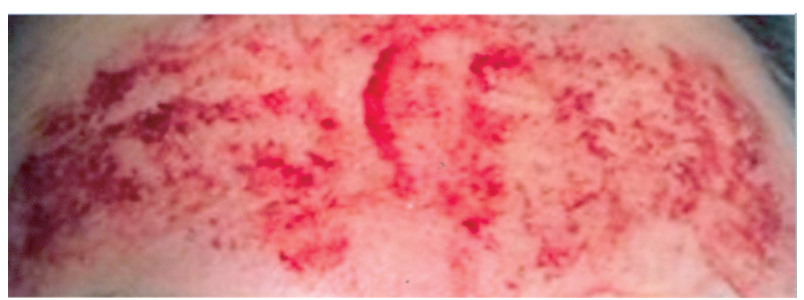

Fig. (3): Treated area after microneedling showing skin bleeding.

Post-procedure directions included proper hygiene with antiseptic soap, which starts after $4 \mathrm{~h}$ of the procedure. The use of healing moisturizer was advised, three to five times a day in order to avoid crust formation. Patients were advised not to remove crusts, these should flake off spontaneously, and to avoid sun exposure throughout the healing time. All the participants were informed to avoid sun exposure for at least 1 month and sunscreen (SPF 60 or greater) was used diligently. Patient were also informed to avoid friction in the treated area and not wearing tight clothes.

Lesions were assessed by clinical examination, digital photograph, Vancouver Scar Scale (VSS), and experienced pain during treatment. Lesions length, width and height were measured at starting point and height were assessed every treatment session according to VSS scale. Pigmentation and vascularity were quantified with clinical examination after blanching with translucent paper: Comparing to surrounding skin and blood refilling, respectively [17].

\section{RESULTS}

During one year, 30 patients were recruited in our study, the mean age of the patients was 28.16 11.24 (range $21-58$ year) and $52 \%$ of patients were female. Lesions location were anterior chest (8), extremities (18) and back (4). The difference re- 
garding lesions location $(p=0.7)$ and VSS scores were not statistically significant.

The mean VSS scores during therapy and follow-up after 3 months were shown in (Table 1).

Based on subject factor repeated measure analysis, there was significant main effect of treatment factor for VSS, pigmentation, pliability, height and vascularity parameters ( $p$-value $<0.001)$, so there was significant improvement in cases of hypertrophic scars treated in this study.

In evaluation of recurrence after 3 months, there was not any significant difference between VSS scores in $9^{\text {th }}$ week $(3.72 \pm 1.05)$ and 3 months after therapy (3.9 \pm 1.12$)(p=0.06)$, the recurrences of pigmentation, pliability, height, and vascularity

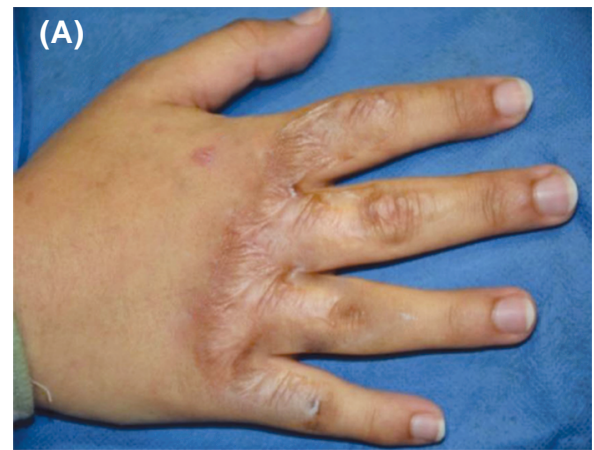

were in $0.6 \%, 10 \%$, and $2 \%$ of treated patients, respectively.

Treatment side effects in week 9 weeks were evaluated which consisted of skin atrophy in 2 patients $(\%)$ and telangiectasia in $6(\%)$.

During treatment 12 patients (40\%) complained from mild burning after treatment sessions most of it was transient and treated easily by cold compresses and simple pain killers.

We also evaluated the effect of therapy on symptoms like pain, pruritus and burning before therapy. At week 0, 13 patients $(43 \%)$ lesions experienced pruritus, burning and pain in their lesions. The results of effect of therapy on these symptoms were shown in (Table 2).

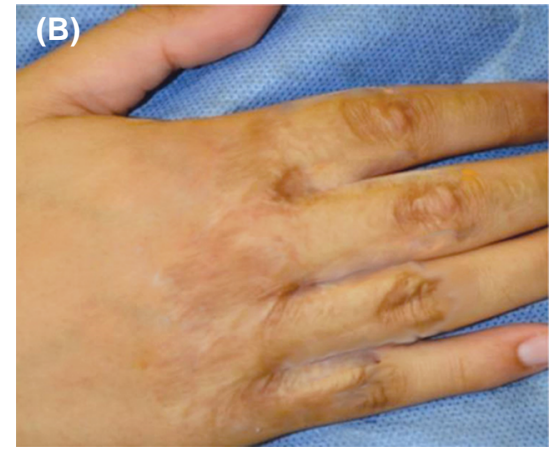

Fig. (4): Post-traumatic hypertrophic scar on the dorsum of the hand. (A) Pre-treatment view (B) Post-treatment view after 3 months.
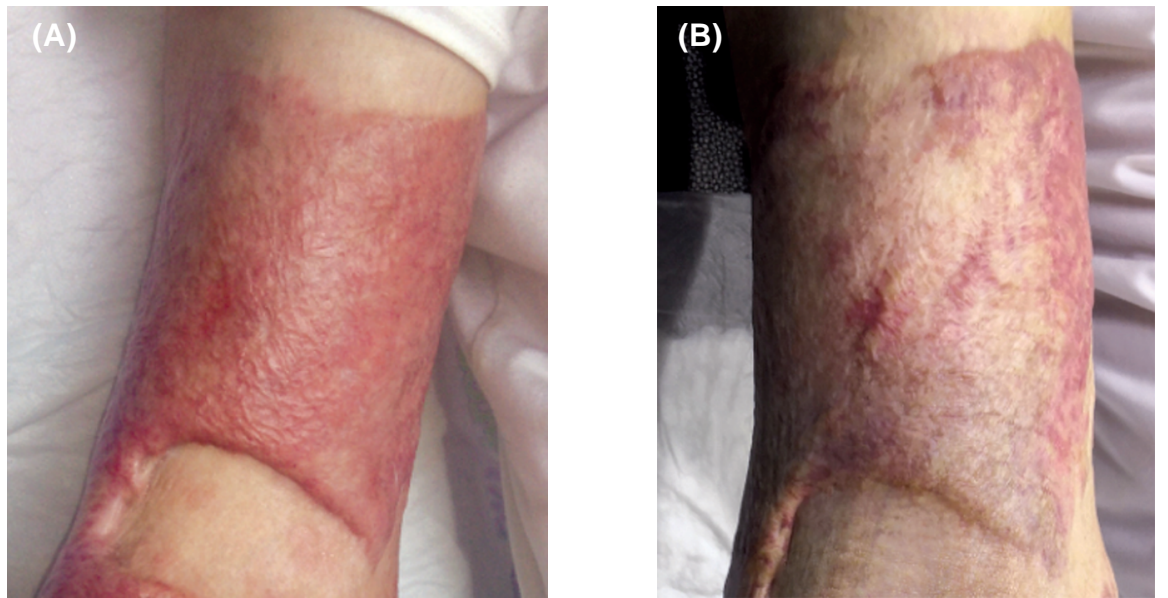

Fig. (5): Post-burn hypertrophic scar on the arm. (A) Pre-treatment view (B) Post-treatment view after 9 weeks.
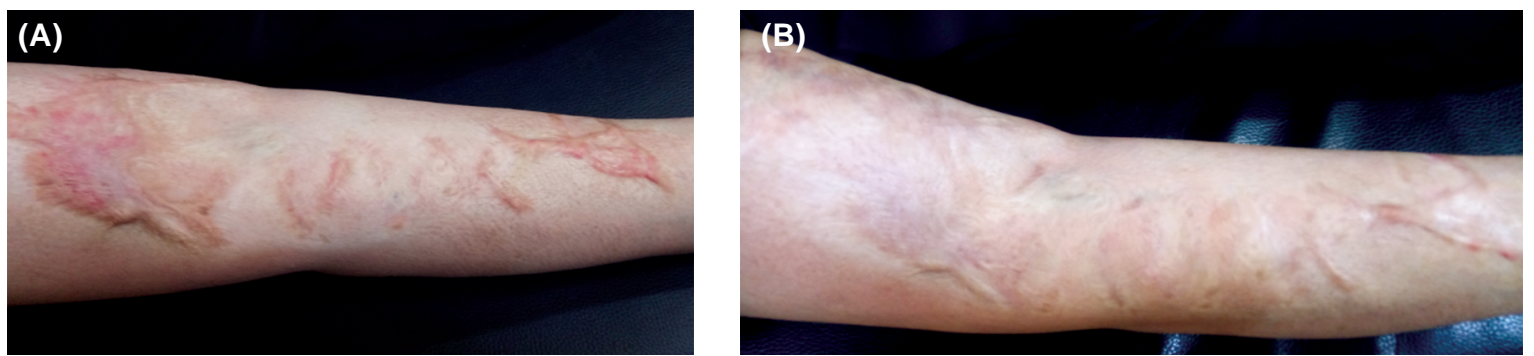

Fig. (6): Post-burn scar on the arm and post-surgical (Z-plasty) on the forearm. (A) Pre-treatment view (B) Post-treatment view after 3 months. 
Table (1): Mean VSS scores during therapy and follow-up.

\begin{tabular}{llcllll}
\hline \multirow{2}{*}{$\begin{array}{l}\text { VSS } \\
\text { parameter }\end{array}$} & Week 0 & Week 3 & Week 6 & Week 9 & Month 3 & $p$-value \\
\cline { 2 - 7 } & $2.63 \pm 0.41$ & $1.96 \pm 0.49$ & $1.18 \pm 0.62$ & $0.6 \pm 0.57$ & $0.22 \pm 0.50$ & $<0.001$ \\
\hline Height & $3.90 \pm 0.78$ & $2.88 \pm 0.65$ & $1.88 \pm 0.79$ & $0.94 \pm 0.76$ & $0.32 \pm 0.62$ & $<0.001$ \\
Pliability & $2.44 \pm 0.50$ & $2.22 \pm 0.54$ & $1.7 \pm 0.54$ & $1.36 \pm 0.45$ & $1.22 \pm 0.41$ & $<0.001$ \\
Vascularity & $2.74 \pm 0.37$ & $2.62 \pm 0.45$ & $2.40 \pm 0.49$ & $2.32 \pm 0.50$ & $2.28 \pm 0.49$ & $<0.001$ \\
Pigmentation & 2.74 .001 & \\
VSS & $11.98 \pm 1.36$ & $9.66 \pm 1.29$ & $7.18 \pm 1.75$ & $5.18 \pm 1.75$ & $4.06 \pm 1.27$ & $<0.001$ \\
\hline
\end{tabular}

Table (2): Symptoms change in the studied cases.

\begin{tabular}{lc}
\hline Symptoms change & Number of patients \\
\hline Improvement & 10 \\
Unchanged & 3 \\
\hline
\end{tabular}

\section{DISCUSSION}

Hypertrophic scars are still a challenge healing pathology, which can cause cosmetic and sometimes functional deformity. Although a multitude of treatment options exist, intralesional corticosteroids are the mainstays of therapy [1-4].

For intralesional treatment triamcinolone acetonide is the most commonly used steroids, a synthetic corticosteroid derived from hydrocortisone with potent anti-inflammatory action [8], whose mechanism of action is the inhibition of fibroblast proliferation and collagen synthesis, increase in collagenase production, and reduction of collagenase inhibitors [3]. This treatment showed variable efficacy from $50 \%$ to $100 \%$ according to literature, but this treatment option is accompanied by high rate of different side effects from atrophy to telangiectasia and pigmentary disorders. On the other hand, injections are painful and sometimes intolerable, and it is also difficult to apply it evenly or distribution is not homogeneous causing localized areas of atrophic lesion [3,4], hence come the use of transepidermal drug delivery to overcome the problems of intralesional injections.

The use of fractional ablative lasers for transepidermal purpose, such as erbium: YAG and $\mathrm{CO}_{2}$ lasers, has been reported in many studies $[\mathbf{1 1}, \mathbf{1 8}$, $19,20]$. To form the micro-channels in epidermis, through which drugs like triamcinolone acetonide can be introduce into the scar and induce its effects.

Issa et al., conducted a study about transepidermal application of triamcinolone assisted by fractional RF associated with the impact US in the treatment of hypertrophic scars. The results showed improvement or complete resolution of the hypertrophic scars with an excellent aesthetic result. This technique was considered less painful than regular injections [13], but both laser and RF still considered more coasty in terms of the cost of the equipment needed to conduct this kind of therapy.

The latest in the transepidermal treatment armamentarium is microneedling [21]. The development of microneedling occurred in 1994. Electroridopuncture (ERP) for skin aging and acne scars was practiced in cosmetic dermatology since 1995 when Orentreich and Orentreich [22] described dermal needling for scars. Camirand and Doucet described needle dermabrasion using a "tattoo pistol" to treat scars [23]. Fernandes developed a more cost-effective management by introducing percutaneous collagen induction therapy with the dermaroller [24].

In our study we use Dermapen to create transepidermal channels which will deliver triamcinolone acetonide into scared tissue. The results showed that method is efficient to deliver the drug used into the scar tissue and to provoke its effects in improving the scar quality, together with reliving its symptoms. Microneedling with Dermapen is a simple, easy to-do, cost-effective, non-ablative, and minimally invasive procedure with excellent results, minimal social downtime and side effects.

The results can be optimized by careful patient selection, skin preparation; protection and choice of an appropriate device are important variables. The cost of the equipment is within reach of any practitioner or patient. Further studies need to be carried out on a larger sample size and also considering skin type of individual for more conclusive results.

\section{REFERENCES}

1- Bock O., Schmid-Ott G., Malewski P. and Mrowietz U.: Quality of life of patients with keloid and hypertrophic scarring. Arch. Dermatol. Res., 297 (10): 435, 2006.

2- O'Sullivan S.T., O'Shaughnessy M. and O'Connor T.P.: Aetiology and management of hypertrophic scars and keloids. Ann. R. Coll. Surg. Engl., 78 (3 Pt 1): 168, 1996.

3- Al-Attar A., Mess S., Thomassen J.M., Kauffman C.L. and Davison S.P.: Keloid pathogenesis and treatment. Plast. Reconstr. Surg., 117 (1): 286-300, 2006. 
4- Gauglitz G.G.: Management of keloids and hypertrophic scars: Current and emerging options. Clin. Cosmet. Investig. Dermatol., 6: 103, 2013.

5- Tanzi E.L. and Aister T.S.: Laser treatment of scarsadvances in dermatologic surgery. Skin. Ther. Lett., 9 (1): 4-7, 2004.

6- Robertson J.C., Hodgson B., Druett J.E. and Druett J.: Pressure therapy for hypertrophic scarring: Preliminary communication. J. R. Soc. Med., 73 (5): 348-54, 1980.

7- Hatamipour E., Mehrabi S., Hatamipour M. and Shirazi H.R.: Effects of combined intralesional 5-fluorouracil and topical silicone in prevention of keloids: A double blind randomized clinical trial study. Acta Med. Iran, 49 (3): $127,2011$.

8- Chrousos G.P. and Margioris A.N.: Adrenocorticosteroid \& cortico-adrenal antagonists in Katzung BG. Basic and clinical pharmacology. $8^{\text {th }}$ ed. The McGraw-Hill: United States of America, 574-89, 2003.

9- Garg G.A., Sao P.P. and Khopkar U.S.: Effect of carbon dioxide laser ablation followed by intralesional steroids on keloids. J. Cutan. Aesthet. Surg., 4 (1): 2-6, 2011.

10- Elsaie M.L., Baumann L.S. and Elsaie L.T.: Striae distensae (stretch marks) and different modalities of therapy: An update. Dermatol. Surg., 35 (4): 563-73, 2009.

11- Gómez C., Costela A., García-Moreno I., Llanes F., Teijón J.M. and Blanco D.: Laser treatment on skin enhancing and controlling transdermal delivery of 5-fluorouracil. Laser Surg. Med., 40 (1): 6-12, 2008.

12- Donelly R.F., Morrow D.I., McCarron P.A., Woolfson A.D., Morrissey A., Juzenas P., Juzeniene A., Iani V., McCarthy H.O. and Moan J.: Microneedle-mediated intradermal delivery of 5-aminolevulinic acid: Potential for enhanced topical photodynamic therapy. J. Control Release, 129 (3): 154-62, 2008.

13- Issa M.C.A., Kassuga L.E.B.P., Chevrand N.S. and Pires M.T.F.: Topical delivery of triamcinolone via skin pretreated with ablative radiofrequency: A new method in hypertrophic scar treatment. Int. J. Dermatol., 52: 36770, 2012.

14- Wolfram D., Tzankov A., Pülzl P. and Piza-Katzer H.: Hypertrophic scars and keloids-a review of their patho- physiology, risk factors, and therapeutic management. Transepidermal Drug Delivery: Overview, Concept and Applications. Dermatol. Surg., 35 (2): 171-81, 2009.

15- Schwarz M. and Laaff H.A.: Prospective controlled assessment of microneedling with the Dermaroller device. Plast. Reconstr. Surg., 127 (6): 146e-148e, 2011.

16- Niwat P.: Percutaneous collagen induction with dermaroller for management of atrophic acne scars in 31 Thai patients. J. Cosmet. Dermatol., 2 (1): 1-13, 2009.

17- Baryza M.J. and Baryza G.A.: The Vancouver Scar Scale: An administration tool and its interrater reliability. J. Burn Care Res., 16: 535-8, 1995.

18- Haerdersdal M., Sakamoto F.H., Farinelli W.A., Doukas A.G., Tam J. and Anderson R.R.: Fractional $\left.\mathrm{CO}_{2}\right)$ laserassisted drug delivery. Laser Surg. Med., 42 (2): 11322, 2010.

19- Stumpp O.F., Welch A.J., Milner T.E. and Neev J.: Enhancement of transepidermal skin clearing agent delivery using a 980nm diode laser. Lasers Surg. Med., 37 (4): 278-85, 2005

20- Wang K.F., Fang J.Y., Hu C.H. and Lee W.R.: Erbium: YAG laser pretreatment accelerates the response of Bowen's disease treated by topical 5-fluorouracil. Dermatol. Surg., 30 (3): 441-5, 2004.

21- Sharad J.: Combination of microneedling and glycolic acid peels for the treatment of acne scars in dark skin. J. Cosmet. Dermatol., 10 (4): 317-23, 2011.

22- Orentreich D.S. and Orentreich N.: Subcutaneous incisionless (subcision) surgery for the correction of depressed scars and wrinkles. Dermatol. Surg., 21 (6): 543-9, 1995.

23- Aust M.C., Reimers K., Repenning C., Stahl F., Jahn S. Guggenheim M., Schwaiger N., Gohritz A. and Vogt P.M.: Percutaneous collagen induction: Minimally invasive skin rejuvenation without risk of hyperpigmentation-fact or fiction? Plast. Reconstr. Surg., 122 (5): 1553-63, 2008.

24- Patnaik V.V.G., Singla R. and Bala S.: Anatomy of 'a beautiful face \& smile'. J. Anat. Soc. India, 52 (1): 74-80 16. Sharad J. (2011) Combination of microneedling and glycolic acid peels for the treatment of acne scars in dark skin. J. Cosmet. Dermatol., 10 (4): 317-23, 2003. 